Article

\title{
Towards A Relational Model for Emerging Urban Nature Concepts: A Practical Application and an External Assessment in Landscape Planning Education
}

\author{
Juanjo Galan $\mathbb{D}$ \\ Department of Architecture, Aalto University, 02150 Espoo, Finland; Juanjo.galan@aalto.fi
}

Received: 10 February 2020; Accepted: 19 March 2020; Published: 20 March 2020

check for updates

\begin{abstract}
The increasing interest in urban nature and its connection to urban sustainability and resilience has promoted the generalized use of new concepts such as green infrastructure, ecosystem services and nature-based solutions. However, due to their heterogeneous origins and interpretations, the usage and understanding of these concepts may vary considerably between different academic and professional groups, affecting their coordinated and synergistic use in integrative planning education and emphasizing the need for the exploration of clearer syntaxes and articulations between them. Accordingly, the main aim of this research was to develop a relational model and to investigate, through an external evaluation process, the benefits that these types of models can provide in higher education and in professional practice. This article presents the background theory and process that led to the development of the relational model, the outcomes of its academic implementation and the results of the assessment of both the model and the students' work by different types of planners, researchers and practitioners. The findings show the potential of the defined relational model to integrate different concepts operating in complex socio-ecological systems and the benefits of developing, testing and validating models by linking research, education and professional practice.
\end{abstract}

Keywords: urban nature; green infrastructures; ecosystem services; landscape planning sustainable urban planning; integrative models; conceptual models; socio-ecological systems

\section{Introduction}

As presented in this introductory section and according to literature, the development of novel urban nature concepts has generated conceptual and operational challenges affecting the understanding of their mutual interconnections and their combined use in education and practice. Accordingly, this article elaborates on the following three research questions: (i) Can emergent urban nature concepts be included in a relational model supporting their integrated use in planning? (ii) How could this proposed model support urban and landscape planning education? and (iii) How would this model and the results of its academic implementation respond to the needs and expectation of decision makers, professionals and specialists from different fields?

A preliminary study of new urban nature concepts and their interconnections revealed that the hybridization between different disciplines and fields of knowledge is generating new concepts, framing the approach to urban nature in landscape and urban planning. However, despite the numerous definitions of urban green infrastructures (UGI), ecosystem services (ESS), nature-based solutions (NBS), urban sustainability and urban resilience, the formation of durable terms and a consistent grammar between them often escapes the boundaries of conventional academic and professional disciplines. This situation becomes particularly noticeable in complex socio-ecological systems such as urban areas, where planning increasingly needs to deal with an expanding number of drivers, 
objectives and interests and in which systems thinking and multidisciplinarity, interdisciplinarity and transdisciplinarity still challenge pre-existing ways of researching and working [1]. Accordingly, scholars have widely recognized, through systematic terminological studies, that the same concepts are frequently understood and are used differently in different groups [2-4]. Thus, there is an urgent need to advance in the definition of relational models connecting them and facilitating their effective and synergetic use by academics, practitioners and decision-makers. According to Van Kamp et al. (2003), the definition of those conceptual models can be based on a theoretical approach exploring hypothetical relationships between concepts, or in an empirical approach indicating factual relationships between the concepts considered. The models arising from those two types of approaches can be combined and can even operate as thinking models when their level of abstraction is such that they cannot be tested. Interestingly, many empirically developed models are based on "more or less coincidental elements (that) are combined into a framework. In the best case these models can function as a point of departure for theory building and thus have heuristics value" [5] (p. 8).

Regarding the practical use of new urban nature concepts by professionals, decision-makers and administrations, and particularly their integrated use in urban nature visions, strategies and narratives, there is also an operational, semantic and syntactic or grammatical challenge that affect the understanding of the concepts, their mutual articulation and their effective implementation. This challenge has been identified by numerous authors in specific concepts such as green infrastructure [6-8], nature-based solutions [4], and ecosystem services [9], as well as in some of their mutual interconnections $[3,10,11]$. However, despite the adequate diagnosis of the challenge and the development of various conceptual and operational frameworks to resolve it, there is an increasing need for clearer evidence on how these concepts are understood, interconnected and used by different stakeholders.

As a consequence of this need for relational models, Pauleit et al. (2017) developed a relational study of different concepts that have emerged recently to enhance nature and promote the benefits that it can provide in urban areas [3]. The central concept in their research was NBS. All the studied concepts were analysed both in terms of their definition and history and their features and elements, and the NBS concept was dually compared in terms of commonalities and differences with all other concepts. After this study, the concepts were studied using two variables: level of operationalization (from highly operational to mainly conceptual) and breadth of the thematic scope covered by each concept.

Similarly, Nesshöver et al. (2017) conducted research to determine the repercussions for science, policy and practice of NBS [4]. The meta-concept or overarching framework was sustainability and its different dimensions. The research included a systematic comparison of definitions and aims for different urban nature concepts. The paper recognized the risk of misunderstandings, duplications and unintended consequences if new concepts are not put into context with existing concepts.

Lafortezza et al. (2013) focused on the UGI concept as a tool to support urban spatial planning in Europe. In this endeavour, the authors aimed to support public health and well-being and established a model in which the green infrastructure framework integrates different functional concepts, such as ecosystem services, human well-being, biodiversity, sustainable development and social and territorial cohesion [10].

Green infrastructures (GI) were also the central concept used by Hansen and Pauleit (2014) to define a conceptual framework for multifunctionality in UGI planning [6]. After presenting the cascade model connecting ecosystems to human well-being [11], and a model connecting multifunctionality with different scales in green systems, the proposed conceptual framework combines conceptual components of GI and ESS to analyse, assess and improve or manage the level of multifunctionality in GIs. A similar approach can also be found in the model proposed by Tzoulas et al. (2007) for promoting human and ecosystem health in urban areas through the use of GI [12].

Alternatively, some authors have focused more on the emergence of new urban nature concepts following the increasing interest in interactions between socio-cultural and biophysical systems. Thus, Tibdall and Krasny, 2010 studied how education can retrofit civic ecology practice and sustainability was 
presented as an umbrella framework, framing biophysical and socio-cultural components connected through the ESS concept [13]. Interestingly, Muhar et al. (2017) concentrated on conceptions, both individual and collective, of human-nature relationships and specific urban nature concepts, such as GI and ESS, which were perceived as part of the "concepts of nature" included in the social-cultural framework developed to link biophysical and socio-cultural systems [14]. The same basic principle lies behind the model proposed by Galan and Perrotti (2019) to explain a regional metabolism through a set of meta-systems (social and physical) and their corresponding systems [15].

Overall, and in accordance with the first research question proposed for this article, the study of existing literature suggests the need for systematically analysing and comparing existing models, in order to identify different typologies and to understand how and how many different urban nature concepts are connected through them and for which purposes. This information would be essential to determine the possible need for new relational models linking urban nature concepts and strengthening the necessary connections between specialized research and integrative practice [6], or between thinking and planning [16,17].

Interestingly, education can play a key role in this regard. Thus, according to Armstrong (1999), the exploration of new ideas can be limited in professional practice due to a range of different economic, operational and logistical reasons. However, higher education in general and planning or design studios in particular can offer an ideal platform to develop and test these new ideas [18], using the possibilities offered by case study research at the same time [19].

Consequently, and from an academic perspective, it becomes pertinent to consider which kind of learning processes can better provide future planners with the cognitive and relational skills needed for working in multi/inter/transdisciplinary environments, where, in addition to the challenge of understanding new emerging concepts, they will need to know how to combine them in a coherent way and how to link them with the multifaceted tasks that characterize spatial, land-use, landscape, environmental and urban planning.

Out of all the available course types, studio courses provide one of the most frequent and advocated options for linking research and practice by applying theory and knowledge to practical challenges [20]. Studios are usually organized as workshop courses in which students and teachers engage in an active learning process and work together, quite often through case studies, in the definition of topics, processes and outcomes [21-24]. In particular, planning studios are increasingly connected with the definition of policies or strategies and with interdisciplinary work to address the new demands of professional practice $[23,25]$. Moreover, studio courses are often not expected to replicate practice but to develop new and better future practices [26].

This explorative and game-changing character of the studio courses has implied a shift from practical training to critical inquiry and has raised new demands for the studios to operate as valid vectors between research and practice or as platforms for the generation of accepted knowledge [18]. This new situation suggests the need for the advancement in the refereed assessment of studio results or in the validation of their processes and results by using quantitative or qualitative methods such as triangulation or crystallization $[18,27,28]$.

With some remarkable exceptions, such as the work of Margoluis et al. (2009) on the use of conceptual models on planning and conservation [29], existing literature on the validation of conceptual, relational or integrative models in urban and landscape planning and of their application in education as a mediator between research and practice is relatively scarce. However, available literature in other system-based fields suggest that this validation can be operated through the use, or combination, of different methods. Thus, according to Oliver-Hoyo and Allen (2006), triangulation can provide a "more accurate and valid estimate of qualitative results for a particular construct" by reviewing and combining data collected through different methods (e.g., interviews, surveys, journal entries and field note entries) [30] (p. 42). Alternatively, validation can rely on a single method. Thus, Mehmood and Cherfi (2009) claim that the functionality of conceptual models in the field of information systems can be empirically validated through a survey "providing feedback from professionals including 
practitioners" and identifying "attributes or factors important to professionals for evaluating the quality of conceptual models". In this specific case, the survey was distributed amongst different types of users and researchers, asking them also their occupation from a predefined list [31].

Similarly, Maes and Poels (2007), highlight the lack of practical evaluation frameworks for conceptual modelling scripts and develop an empirical test for a proposed model based on four quality dimensions from a user perspective (semantic quality, ease of understanding or systemic quality, usefulness and user satisfaction) and structured around two experiments with students. The results supported the suggested model and provided relevant inputs for both theory and practice [32].

The possibility of framing the development of a relational model about urban nature concepts and testing it within the landscape architecture field opens up specific challenges and possibilities. Thus, from a disciplinary point of view, urban nature has been a central element in many disciplines, in which the landscape concept has usually been perceived as an integrative platform combining the spatial, functional, dynamic, formal, ecological, socio-cultural and economic aspects of nature and linking them with other dimensions of socio-ecological systems. In this endeavour, landscape architecture has been supported by its classical branches: landscape planning and design; and has been accompanied by other disciplines, such as landscape urbanism, ecological urbanism, landscape ecology and urban ecology, amongst others [33-36]. Moreover, the "landscape architecture" contribution to urban nature planning and management could specifically be placed in the integration of different types of knowledge, in the exploration of their mutual intersections, in the generation of new synergies and, consequently, in the design of schemes in which space and function, as well as pattern and process, display high levels of multifunctionality [37].

Accordingly, if human knowledge constitutes a densely interconnected web [38], landscape architecture - because of its highly integrative and transversal nature-could be seen as an extremely connected node with a particular sensitivity to changes in peripheral or close disciplines. Furthermore, this strategic or nodal location imposes additional challenges in landscape architecture education, especially when those related disciplines undertake significant methodological or theoretical changes or when new values or planning paradigms arise [37]. This highly connected character of landscape architecture in particular [39,40], and of the landscape concept in general $[33,41]$, has been widely recognized and reveals some clear parallelisms with general systems theory [42], and with systems properties such as sustainability or resilience.

In conclusion, this literature review suggests the pertinence of advancing in the development of conceptual and relational models combining different urban nature concepts for more integrated use in education and practice (research question 1). In addition, it reveals the potential of education and planning studios to bridge research and innovative practice, raising at the same time the necessity of exploring how the development and testing of such relational models can be integrated in planning education (research question 2). Finally, the selected literature highlights the importance of validating these kind of models and their results through a reliable evaluation method, in which the features and concepts included in the model, and their combined use, are assessed by the final users (research question 3). The development of this research within the field of landscape planning education and practice generates specific opportunities and challenges based on its highly transversal and interdisciplinary character.

\section{Methods}

Due to their very different natures, the three formulated research questions required different research methods. Firstly, the definition of a relational model integrating the studied urban nature concepts was initiated through a selective literature review that revealed some of the most relevant texts dealing with the connection between different urban nature concepts and their respective definitions. This selection was implemented by using different combinations of the following keywords in Google Scholar: GI, UGI, ESS, NBS, models, conceptual models, relational models, landscape, urban sustainability, urban nature and planning. The identified texts were filtered in order to select those 
with a clearer focus on relational models covering two or more concepts or including a systematic comparison of more concepts. The selected concepts correspond to those more often mentioned in existing models for urban nature and planning. Some other concepts appeared frequently in many texts, either as key characteristics of the urban nature system (e.g., biodiversity) or as key goals (human well-being or quality of life) and were retained in the elaboration of the final relational model. The ongoing discussion on how the biodiversity concept relates to the ecosystem services concept is highly connected to how the former concept is approached [43], either as a benefit for humans, hence as an ecosystem service [44], or as a goal in itself. On the other hand, existing literature analysing the connections between the sustainability and the biodiversity concepts, suggests that biodiversity is a precondition for ecosystem function and for the generation of some ESS, and therefore, is directly connected with the economic, social and environmental $[45,46]$.

The selected relational models were analysed to understand the criteria used in each of them to connect the addressed concepts. Different typologies of models emerged from this process. Simultaneously, the definitions used for the studied concepts in the selected texts, together with some definitions found in seminal or authoritative documents (e.g., European guidelines), were compared in order to produce an internal glossary of terms supporting the subsequent development of a new relational model. This glossary was accompanied by a categorization of the urban nature concepts according to their main potential and complementary roles in urban nature planning.

Secondly, the proposed relational model was considered to redefine the goals, contents, learning methods and structure of a seven credits compulsory course at the Aalto University Master's Programme in Landscape Architecture (studio course MAR-1025). The selection of one academic studio course to test the application of the model was based on the reasons presented in the introduction, namely the importance of developing conceptual and relational skills in future planners and the possibilities for flexible and solid speculation provided by higher education and for linking research with innovative practice $[18,20,23,24,26]$. In particular, this new version of the course assigned a pivotal role to the studied concepts in the definition of strategic visions for urban nature systems in a set of Baltic and Finnish cities (Helsinki, Espoo, Tampere, Turku, Oulu, Lahti and Mikkeli in Finland, Gävle and Söderham in Sweden, Riga and Jelgava in Latvia and Tartu in Estonia). The proposals, produced during the academic years 2016-2017, 2017-2018 and 2018-2019, were synthetized and displayed by each group of students in a set of posters that were later evaluated by external experts, according to a set of criteria and objectives.

In particular, the studio course was structured around the following assignments: (1) morphological, social, functional and historical analysis of the studied cities; (2) analysis and diagnosis of the cities using the studied urban nature concepts (urban blue-green infrastructure, ecosystem services, nature based solutions and their potential connections to urban sustainability); (3) definition of city strategies and pilot actions based on the proposed relational model and aimed at improving urban sustainability in the studied cities.

Thirdly, and following one of the methods presented in the introduction to validate conceptual models [31,32], the potential of the suggested relational model for responding to real urban nature planning challenges and to support innovative education was evaluated through a questionnaire delivered to different types of stakeholders or users, who assessed both the model and the outcomes produced by the students. The questionnaire included three types of questions. The first type included open questions to determine the job sector, former education and professional field of the respondents. The second type assessed the respondent's familiarity and level of use with the different urban nature concepts included in the relational model (UGI, ESS, NBS, etc.), as well as their acquaintance with any integrative model or framework connecting the concepts in question. The third type of questions requested the opinion of the respondents on the effectiveness and utility of the proposed integrative model to support urban sustainable planning, both at a general level and in the specific works produced by the students in their respective Baltic or Finnish City. Questions included in the second and third 
type were formulated as closed-ended questions using a Likert scale in which the score 1 indicated a strong disagreement or low grading, and 5 strong agreement or high grading.

The survey was sent to 75 people including 51 civil servants working in the studied cities, 12 teachers/researchers from different disciplines working with some of the studied urban nature concepts and 12 practitioners from landscape architecture offices, as that was the discipline in which the course was organized. The composition of the sample was also defined in order to include respondents with different academic backgrounds or professional foci (e.g., from integrative to specialized planning or from spatial design to city management).

The results were analysed to assess the general effectiveness and utility of the proposed relational model to support sustainable urban-planning and its potential to help students articulate the studied concepts. In addition, this quantitative study permitted the detection of possible convergences and divergences between respondents with different academic backgrounds, professional fields or job sectors, as well as possible differences between distinct groups regarding their level of knowledge and use of the studied concepts. However, due to the small sample size, statistical analyses of the data had serious limitations and hindered the detection of significant differences, correlations or connections in the analysed variables (e.g., effect of the level of knowledge of some concepts or academic background in the evaluation of the students' works).

\section{Results}

The presented results correspond to the three research questions which originated in the conducted research and were explored through the three research methods explained in the previous section.

\subsection{A Relational/Integrative Model for Urban Nature Concepts (Can Emergent Urban Nature Concepts be Included in a Relational Model Supporting their Integrated Use in Planning?)}

The analysis of the studied models connecting different urban nature concepts revealed the existence of some general model typologies. The diversity found in the studied models is highly dependent on the different objectives, criteria and ways to conceptualize themes connected to urban nature. Thus, and as detected in other abstract concepts such as urban environmental quality, human well-being, quality of life and sustainability [5], different authors assign different meanings to the same terms. Moreover, they also have dissimilar approaches to some fundamental questions such as the meta-concepts framing the model (e.g., sustainability), the domains that are used to address these meta-concepts or the applicable spatial or temporal scales or scopes.

Following these findings, we decided to start the definition of the proposed relational model by developing a glossary of the considered concepts. As displayed in Table 1, this glossary included the most widely accepted definitions and preferability-those that also referred to other concepts. The key selected meta-concept framing the definition of the relational model was urban sustainability and its different environmental, socio-cultural and economic domains.

The typological classification of the studied relational models was initiated by the differentiation between topological and chorological approaches proposed for analysing the landscape by Ahern (1999). Thus, "topological analysis is a parametric approach which describes and analyzes the "vertical" relationships between many factors that occur at a given location ... In landscape ecological planning, the topological approach is complemented, not replaced by, a chorological approach which describes and analyses horizontal relationships and flows" [33] (p. 179). 
Table 1. Review of the main definitions, aims and potentials of different urban nature concepts in urban planning (adapted and extended from Galan, 2019 [10]).

\begin{tabular}{|c|c|c|c|}
\hline $\begin{array}{c}\text { Urban Nature } \\
\text { Concept }\end{array}$ & Main Definition(s) Considered the Purpose of the Proposed Relational Model & Main Dimension & Main Use in Sustainable Urban Nature Planning \\
\hline $\begin{array}{l}\text { Urban green-blue } \\
\text { infrastructure (UGI) }\end{array}$ & $\begin{array}{l}\text { "A strategically planned network of natural and semi-natural areas with other environmental } \\
\text { features designed and managed to deliver a wide range of ecosystem services... This network of } \\
\text { green (land) and blue (water) spaces can improve environmental conditions and therefore } \\
\text { citizens' health and quality of life. It also supports a green economy, creates job opportunities } \\
\text { and enhances biodiversity" [47]. }\end{array}$ & Spatial & $\begin{array}{l}\text { Currently the use of the UGI concept in urban planning as a } \\
\text { spatial network is relatively well-established [3]. However, the } \\
\text { connection with other concepts is sometimes unclear. UGIs can } \\
\text { support a more systemic and delimited approach to the } \\
\text { generation of ESS and to the use of NBS. }\end{array}$ \\
\hline $\begin{array}{c}\text { Ecosystem } \\
\text { services(ESS) }\end{array}$ & $\begin{array}{l}\text { ESS are defined as the benefits people obtain from ecosystems and are usually divided into } \\
\text { supporting, regulating, provisioning and cultural services [ } 48 \text {. According to Daily et al. (2011), } \\
\text { if natural capital is the stock of nature's assets, ESS can be understood as the benefits resulting } \\
\text { from those assets [49]. }\end{array}$ & $\begin{array}{l}\text { Functional (Benefits) } \\
\text { (linking processes, } \\
\text { services and benefits) }\end{array}$ & $\begin{array}{l}\text { ESS can support the definition, implementation and management } \\
\text { of UGI and NBS by revealing and systematizing the benefits } \\
\text { provided by nature [3]. Although the ESS concept fosters a } \\
\text { holistic approach to nature with a focus on benefits for humans, } \\
\text { the subdivision of the concept into categories and independent } \\
\text { services can generate partial approaches or the inconsistent } \\
\text { aggregation of different services. }\end{array}$ \\
\hline $\begin{array}{l}\text { Nature-based } \\
\text { solutions } \\
\text { (NBS) }\end{array}$ & $\begin{array}{l}\text { According to the European Commission (2015), NBS are "solutions that are inspired and } \\
\text { supported by nature, which are cost-effective, simultaneously provide environmental, social and } \\
\text { economic benefits and help build resilience. Such solutions bring more, and more diverse, nature } \\
\text { and natural features and processes into cities, landscapes and seascapes, through locally adapted, } \\
\text { resource-efficient and systemic interventions" [50]. Maes and Jacobs (2015) connect the NBS } \\
\text { concept with the natural capital concept by associating NBS with "any transition to a use of } \\
\text { ecosystem services with decreased input of non-renewable natural capital and increased } \\
\text { investment in renewable natural processes" [51]. }\end{array}$ & $\begin{array}{l}\text { Instrumental (Tool } \\
\text { And Solutions) for } \\
\text { multiple and often } \\
\text { systemic problems }\end{array}$ & $\begin{array}{l}\text { According to Haase (2016), NBS can mediate the interaction } \\
\text { between human activities and ecosystem processes in cities and, } \\
\text { if adequately designed and managed, they can mitigate human } \\
\text { impact. NBS should consider the full spectrum of land uses in } \\
\text { cities as well as the co-existence and potential synergic interaction } \\
\text { between built, grey, brown, green and blue systems [52]. }\end{array}$ \\
\hline $\begin{array}{l}\text { Sustainable drainage } \\
\text { systems (SUDS) }\end{array}$ & $\begin{array}{l}\text { SUDs consist of different approaches to manage storm water and runoff, with special attention to } \\
\text { water quantity, water quality, biodiversity and amenity (e.g., flooding, pollution, wildlife and } \\
\text { recreation) [53]. Conceptually, SUDs can be embedded within Sustainable Storm Water } \\
\text { Management and is highly connected to other water related terms. }\end{array}$ & $\begin{array}{c}\text { Instrumental Or } \\
\text { Mediating (Tool And } \\
\text { Solutions) for Storm } \\
\text { Water Management } \\
\text { and for other linkable } \\
\text { ESS } \\
\end{array}$ & $\begin{array}{l}\text { SUDs can play a key role in Sustainable Storm Water } \\
\text { management, promoting at the same time the generation of } \\
\text { different water-related or dependent ESS as well as the } \\
\text { connectivity of GIs by connecting it with the continuous } \\
\text { character of water flows. }\end{array}$ \\
\hline $\begin{array}{l}\text { Socio-ecological } \\
\text { system } \\
\text { (SES) }\end{array}$ & $\begin{array}{l}\text { According to Glaser et al. (2008), a socio-ecological system (SES) "consists of 'a bio-geo-physical' } \\
\text { unit and its associated social actors and institutions". They are complex, adaptive systems and } \\
\text { their boundaries respond to the spatial or functional limits of the affected ecosystems and their } \\
\text { context [54]. Socio-ecological thinking (SET) could be defined as a way of thinking especially } \\
\text { concerned with the sustainable interaction between bio-geophysical systems and humans [37]. }\end{array}$ & $\begin{array}{c}\text { Systemic and } \\
\text { cognitive framework }\end{array}$ & $\begin{array}{l}\text { SES provides a new, systemic and integrative lens to address the } \\
\text { relationship with nature in all types of landscapes. In fact, cities } \\
\text { can be approached as a family of socio-ecological systems with } \\
\text { specific conditions for the use of GI, ESS and NBS imposed by the } \\
\text { urban condition [37]. }\end{array}$ \\
\hline $\begin{array}{l}\text { Urban metabolism } \\
\text { (UM) }\end{array}$ & $\begin{array}{l}\text { There are multiple definitions and methodological approaches to the metabolism of } \\
\text { socio-ecological systems. Because of its generalized use and potential connections to planning, } \\
\text { the approach proposed in the field of industrial ecology can be particularly relevant to investigate } \\
\text { connections with urban nature concepts. Thus, according to Baccini (2007), urban metabolism } \\
\text { provides a model and metaphor to describe and analyse material and energy flows within cities } \\
\text { and to investigate the interactions of natural and human systems [55]. In the same vein, Kennedy } \\
\text { et al. (2007) define UM as the addition of the "technical and socioeconomic processes that occur } \\
\text { in cities, resulting in growth, production of energy, and elimination of waste" [56] (p. 44). }\end{array}$ & $\begin{array}{l}\text { Systemic and } \\
\text { methodological } \\
\text { framework (a type of } \\
\text { model to approach, } \\
\text { analyse, plan and } \\
\text { manage } \\
\text { socio-ecological } \\
\text { systems like cities) }\end{array}$ & $\begin{array}{l}\text { UM provides a quantitative framework for modeling and } \\
\text { planning socio-ecological systems like cities, usually from a } \\
\text { material and energy point of view. } \\
\text { This framework can support the analysis and planning of GI, ESS } \\
\text { and NBS in order to deepen the connections between social and } \\
\text { ecological systems and to increase the performative character of } \\
\text { urban nature for sustainable urban planning and key urban flows } \\
\text { (e.g., water, energy, waste, biota, etc.). }\end{array}$ \\
\hline Natural capital (NC) & $\begin{array}{l}\text { NC can be defined as a stock of natural assets that can produce a sustainable flow [57]. This stock } \\
\text { can yield direct or indirect benefits to humans and can include living and non-living components } \\
\text { of the natural system [4,57]. The concept of NC can be extended, and some researchers include } \\
\text { the information stored in natural systems [58], or the services and benefits provided by them [59], } \\
\text { although the latter are usually separated [4]. }\end{array}$ & $\begin{array}{l}\text { Integration of } \\
\text { nature-based assets } \\
\text { and dimensions } \\
\text { sustaining sustainable } \\
\text { flows. } \\
\end{array}$ & $\begin{array}{l}\text { In its wider and most integrative sense, NC can be defined as a } \\
\text { stock of resources embedded in natural systems and allowing } \\
\text { sustainable flows and processes. Accordingly, urban NC could } \\
\text { comprise the spatial (UGI), human benefits-based (ESS) and } \\
\text { mediating or instrumental (NBS, SUDS) components of nature. }\end{array}$ \\
\hline
\end{tabular}


This differentiation between overlapping or layered dimensions of the same phenomenon or landscape, and the horizontal connections between different components of a given system or landscape, was used to define three types of models and relationships between concepts (Figure 1). The first type is an "embedding" model (nesting dolls) in which concepts are nested within each other. This type of model is highly hierarchical, and the external concepts absorb conceptually and/or spatially the internal ones. The second type is a horizontally "complementary" model, in which the concepts deal with different physical elements, spaces or issues. In this complementary model, some concepts might partially overlap, generating a new conceptual space (e.g., intersections in a Venn diagram). The third type is a "layered" model in which the concepts express or contain a different dimension of the same space, system or phenomenon. This type of model can also be perceived as one that works with vertical and highly interconnected complementarities or interdependencies. In a way, the well-known diagrams used to differentiate strong and weak sustainability can illustrate the difference between an embedded and complementary model for the same concepts (social, economic and environmental sustainability). On the other hand, the different attributes associated to a given spatial unit in a geographical information system exemplify how a layered system works and acknowledges the possible interdependencies between different overlapping attributes.

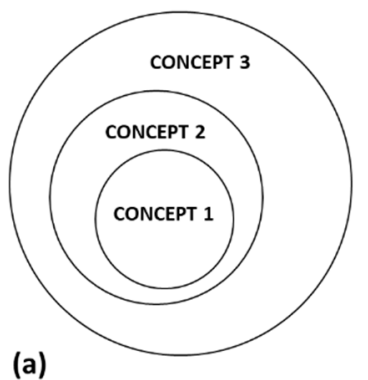

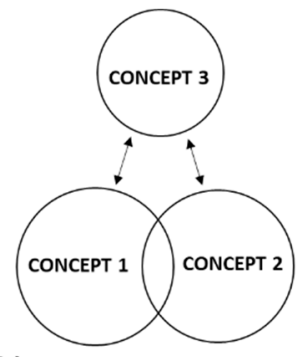

(b)

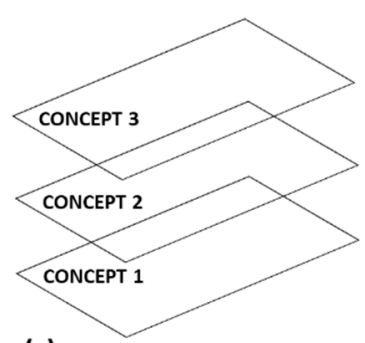

(c)

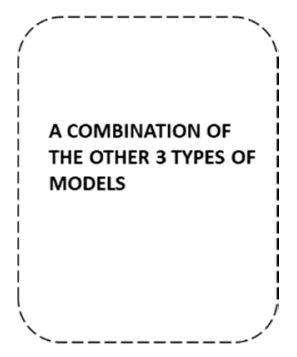

(d)

Figure 1. Main typologies in relational models: (a) embedded, (b) complementary (and horizontal intersections), (c) layered (vertical complementarities and intersections), (d) different combinations of (a-c).

The relational models included in the selected literature were often generated to support a particular theoretical or operational framework proposed by the authors. In many cases, this situation affected the types of connections explored in the models. In addition, rather than focusing on urban nature, many of the models grew around one specific concept that often gained a particular relevance and in many cases was perceived as an umbrella concept embedding the others.

The study of the selected relational models was systematized considering the following aspects: existence of a meta-concept; considered domains; scope; existence of a central concept; inclusion of a terminological analysis; main purpose and variables considered to explore connections between concepts; type of model according to Figure 1.

The results of the studied relational models from a typological perspective reveal that the model developed by Pauleit et al. (2017) can be described as a combination of an embedded and complementary model in which the NBS concept was perceived as an umbrella concept integrating the spatial dimension of urban green infrastructures (UGI) and the benefits provided by nature (ESS) [3]. Likewise, the model proposed by Nesshöver et al. (2017) included nature-based solutions as an umbrella concept or framework, amongst others, to promote more sustainable socio-ecological systems [4]. Similarly, Tibdall and Krasny (2010) considered sustainability to be an overarching framework and defined GI as a biophysical component and ESS as an interface with the socio-cultural component [13].

Conversely, Lafortezza et al. (2013) established an embedded model in which the GI framework includes different concepts and functions [10], whereas Hansen and Pauleit (2014) defined a layered model in which the spatial dimension of the GI is connected to its functional dimension in terms 
of benefits for human well-being (ESS) [6]. In their model, Tzoulas et al. (2007), followed a similar approach and layered arrangement [12], whereas Galan and Perrotti (2019) explained the metabolic performance of a regional socio-ecological system through a set of layered meta-systems (social and physical) and their embedded systems [15].

An overall review of the typological arrangements of concepts in the studied models shows that one of the key variables is the definition of an overarching concept, which, depending on the model, concentrates on the goal or purpose (e.g., sustainability) or on the prevalence of one concept over the others. In addition, the results prove that the relationships between concepts is highly dependent on how they are defined, since these definitions generate different associations: insertion (embedded model), complementarity or juxtaposition (layered models).

Regarding the terminological research displayed in Table 1, a systematic review of the new urban nature concepts used in the studied literature and relational models, reveals that they usually operate or emphasize different purposes or semantic levels (e.g., spatial, functional, instrumental, cognitive or guiding). In order to advance in the production of a relational model for urban nature concepts, specific definitions were chosen for the considered concepts and their main aims and potential use in urban nature planning were inferred from the studied literature. The selection of definitions was based on their broad acceptance by researchers, practitioners and decision-makers while the identification of their main aims was based on the definitions themselves and on the search for complementary aims between concepts, to avoid duplications.

The resulting relational model is a combination of a layered model in which space and function, in this case GI and the benefits generated within it (ESS, human well-being and biodiversity if understood as an ecosystem service), are layers of the same entity (urban nature) and in which other concepts have the capacity to affect the generation of benefits in the spatial infrastructure (NBS, SUDS, etc.). In addition, other concepts embed the urban nature concept, giving purpose or direction to its planning or management (e.g., urban sustainability, resilience, quality of life or biodiversity when this last concept exceeds the pure anthropocentric perspective and is understood as a precondition for sustainability), or approaching it from a specific perspective (e.g., natural capital).

As presented in Figure 2, urban sustainability and resilience, together with biodiversity and well-being, could ideally operate as overarching and guiding frameworks, setting dynamic goals or processes for the evolution of urban socio-ecological systems and supporting systemic and transdisciplinary ways of thinking. The proposed model emphasizes the spatial dimension of urban green-blue infrastructures that, following some of the most extended and recent definitions of the term [47], are perceived as spatial networks where different types of nature and nature-associated processes take places in cities. These infrastructures are understood as basic components for the functioning of the urban socio-ecological system and, from an anthropocentric perspective, have the capacity to increase human well-being by delivering an extensive range of benefits or ESS [11,12,47,52]. In fact, the adequate and rigorous consideration of those benefits can be used to objectively assess the performance of green-blue infrastructures and support their improvement. Conversely, the structure, composition, characteristics and functioning of each green-blue infrastructure greatly determines its capacity to generate ESS and this capacity or performance can be managed or adjusted by using features, structures or elements assisted by nature and natural processes (e.g., NBS, SUDs, etc.). Furthermore, in accordance with the suggested relational model, the combination of the benefits and spatial-functional dimensions of urban nature, together with the instruments or tools facilitating its normal or amplified performance, could be understood as overall urban nature capital [37]. 
COGNITIVE AND METHODOLOGICAL SYSTEMICFRAMEWORKS: SOCIO-ECOLOGICAL SYSTEMS, SOCIOECOLOGICAL THINKING, URBAN METABOLISM

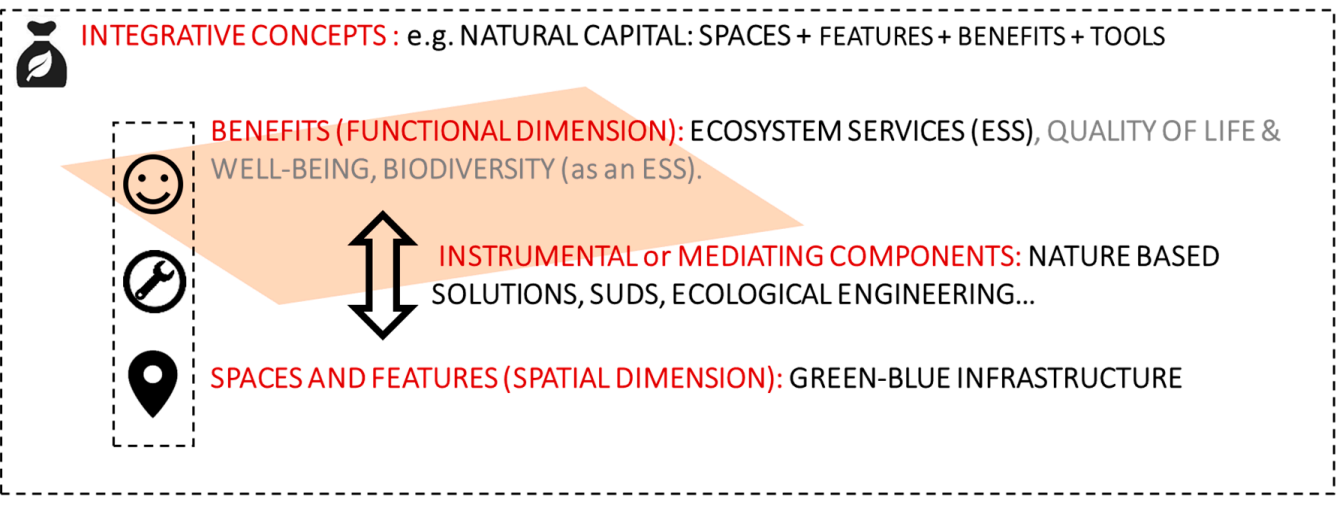

Figure 2. A potential relational model for urban nature concepts supporting urban sustainability and resilience (adapted from Galan, 2019 [10]).

All these concepts can operate under the umbrella of urban sustainability and resilience and support the approach to the city as a socio-ecological system in which humans and the "other nature" are deeply intertwined and can achieve higher levels of synergy and hybridity. In addition, this model considers the connection between highly performative urban nature systems and the transition towards more sustainable urban metabolisms by analysing the potential contributions of urban nature in material, water and energy flows.

\subsection{Students' Application of the Proposed Relational Model in a Set of Baltic/Finnish Cities (How Could a Proposed Relational Model for Urban Nature Concepts Support Urban and Landscape Planning Education?)}

The role of the proposed relational model in the Aalto University Green Area Planning course was to promote sustainability transitions in Finnish and Baltic cities through the transformation and improvement of their urban nature systems in general, and of their blue-green infrastructures and associated ecosystem services in particular. The model provided a methodological and conceptual framework combining different urban nature concepts and aimed at increasing the performance of urban nature and its capacity to generate well-being and influence urban metabolisms, urban morphology and urban ways of living [37]. In addition, the model tried to help the students understand and explore the connections between the concepts and how they can be used effectively and synergistically in urban and landscape planning.

The course was organized in different phases in which students progressively explored the considered concepts, analysed their potential linkages and familiarised themselves with various quantitative and qualitative methods supporting the analysis and upgrading of urban nature systems for the studied cities and their functional units (urban landscape types, urban functional areas or typological urban areas). The definition of functional urban units challenged the dichotomist division between green and urban, and approached the city as a collage of different landscape types conformed by particular combinations of green types, building types and land-uses, at the same time allowing for the inclusion of new types of unplanned and dispersed elements of nature.

Overall, the outcomes and deliverables produced during the course revealed an adequate articulation amongst the studied urban nature concepts and an increased capacity of the students to think both conceptually and systemically. Moreover, the results of the course displayed a remarkable level of exportability and scalability, as well as a good connection between the upgraded urban nature systems and the overarching goal of increasing the levels of sustainability and resilience in urban socio-ecological systems. In a wider sense, the acquired skills and knowledge were expected to 
reinforce the students' capacity to become engaged in broader urban discussions both as part of their studies and of their future professional or research practice (Figures 3 and 4).

Figures 3 and 4 show some examples of work produced by the students. The matrix located in the upper part of Figure 3 displays how, in the city of Oulu (Finland), different urban green types (columns) can generate different types of ESS (rows with pie charts presenting regulating, provisioning and cultural ESS, as well as their overall aggregation). The urban green-blue infrastructure was approached as a combination of different green types and the city as a collage of landscape types characterized, amongst other factors, by the particular qualities of their green-blue infrastructure and the specific ESS provided by it. Figure 3 also includes a map in its lower half, displaying the location of each urban green type and suggesting - together with other physical, functional and perceptual factors-the main landscape types in the city of Oulu (Finland).

\section{GREEN INFRUSTRUCTURE AND ECOSYSTEM SERVICES (CITY OF OULU)}

Ecosystem services provided by each type of area in the green and grey infrastructure.

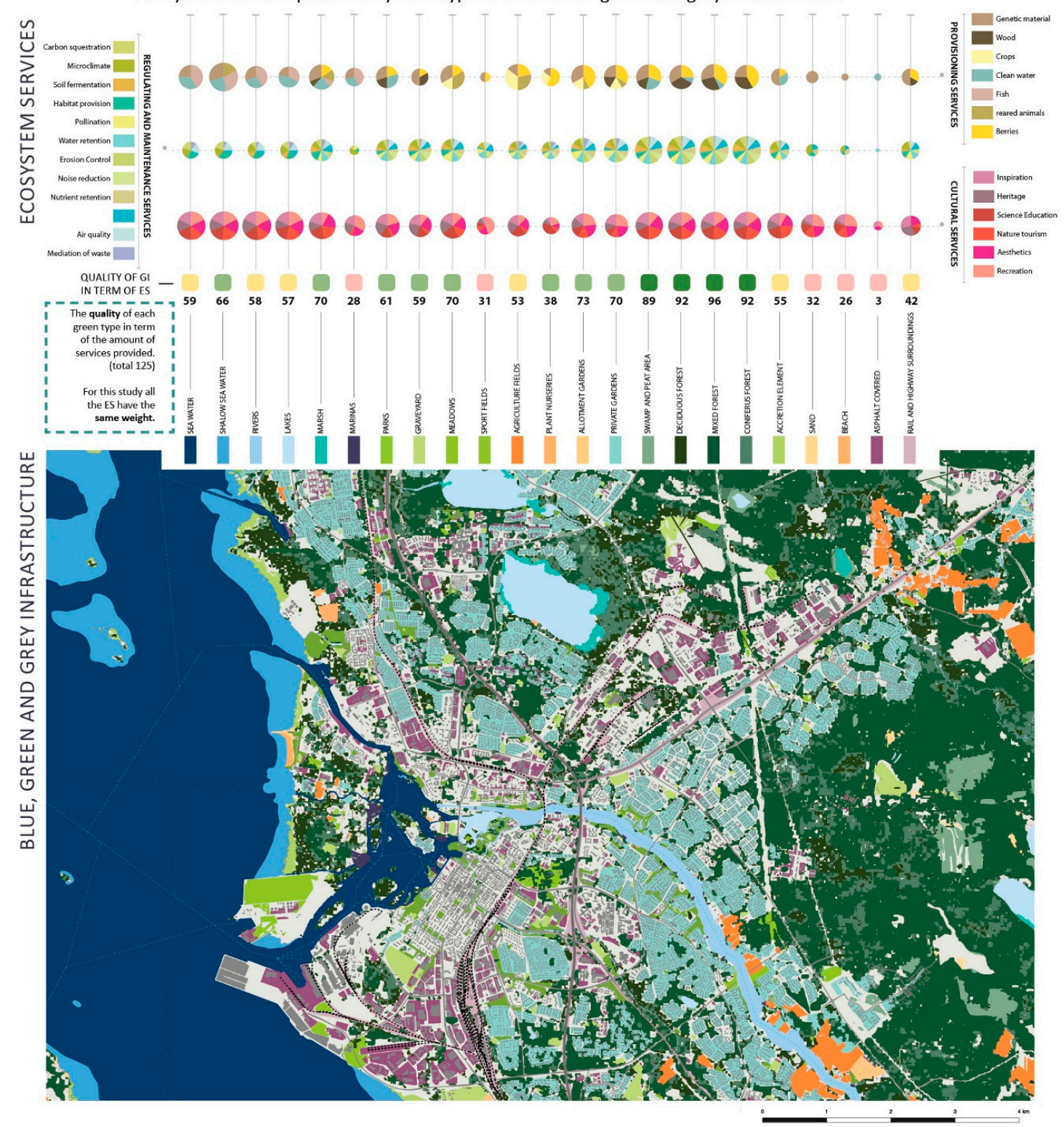

Figure 3. Green types, ecosystem services and blue-green infrastructure in the city of Oulu (Finland). Students: F. Bourgeau, O. Mahlio, H. Poutanen and H. Torkkeri, Teacher: J. Galan (2017). 
INCREASING THE QUALITY OF GREEN INFRASTRUCTURE AND ECOSYSTEM SERVICES (CITY OF ESPOO)

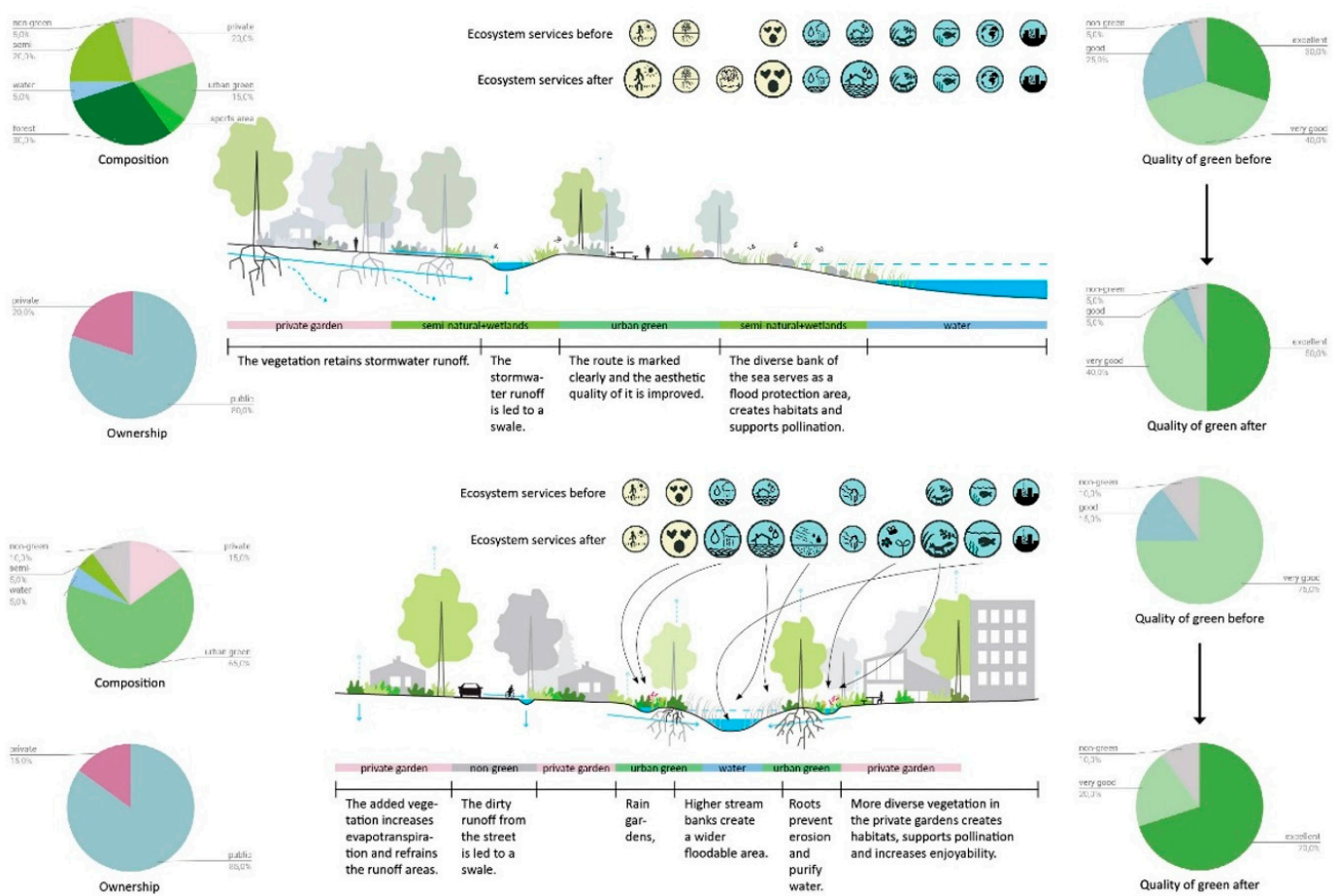

IMPROVING GREEN INFRASTRUCTURE AND ECOSYSTEM SERVICES (CITY OF TURKU)

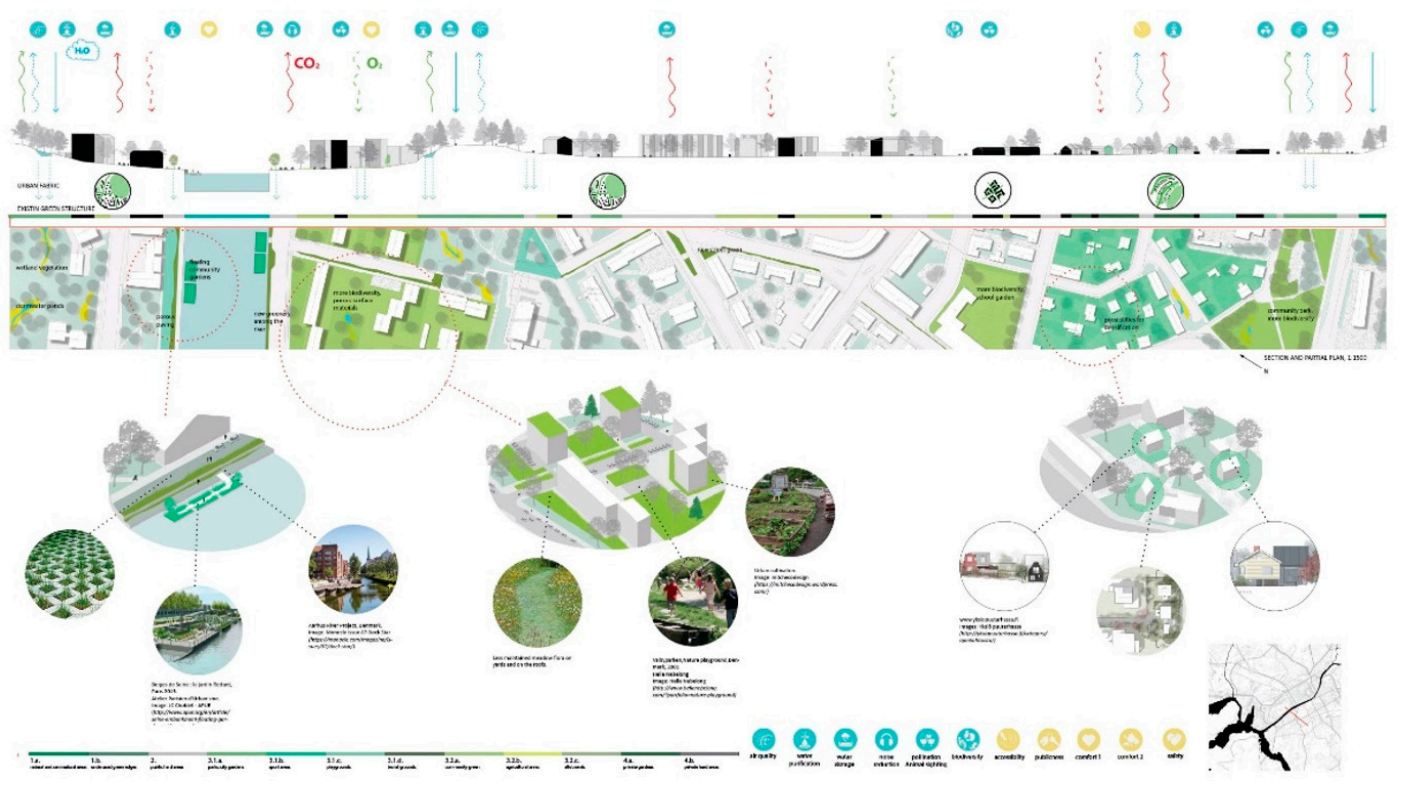

Figure 4. TOP: Increasing urban nature performance by improving the quality of blue-green infrastructure through the generation of more and more diverse ecosystem services (Espoo, Finland). Students: S. Aalto, J. Jääskeläinen, D. Mavliutova and S. Palmu. Teacher: J. Galan (2017); BOTTOM: Upgrading blue-green infrastructures, ecosystem services and the contribution of urban nature in the metabolism of different types of urban fabrics (Turku, Finland). Students: M. Paija, E. Renkoven, S. Sawada and A. Puska; Teacher: J. Galan (2016). 
Figure 4 displays specific proposals derived from the integrated analysis of blue-green infrastructure, ecosystem services and urban metabolisms in the cities of Espoo and Turku (Finland). In particular, the two sections at the top of Figure 4, show how adjustments in two prototypical urban transects in Espoo (Finland), can have a significant effect on the performance of its blue-green infrastructure and its constituent green types. The pie charts on the left display the proportions of each green type in the blue-green infrastructure of each urban or landscape type and are accompanied by a second pie chart explaining the type of ownership (public or private). The proposed improvements would produce a significant increase in the performance or quality of the addressed green types, as well as of the total blue-green infrastructure. These results are aligned with the strategic proposals developed in some European cities to make densification and greening compatible and to generate more ESS without increasing the overall area of the blue-green infrastructure [60].

It is important to remark that, arguably, for the purpose of the development of these proposals, the quality of a particular green area was connected with the intensity and variety of the ESS produced within it. In the end, this approach promoted higher levels of vertical or site-related multifunctionality but was lacking a more systemic character that was partially achieved by introducing other strategies usually based on horizontal properties, flows and connectivity. As displayed in the lower part of Figure 4, the same principles were applied in different urban areas of the city of Turku (Finland), generating similar types of outcomes.

3.3. External Assessment of the Proposed Relational Model and Its Application by the Students in a Set of Baltic/Finnish Cities (How Would the Proposed Relational Model and the Results of Its Academic Application Respond to the Needs and Expectation of Decision Makers, Professionals and Specialists from Different Fields?)

Planners, researchers and practitioners assessed the proposed relational model and its implementation by students of the green area planning course after reviewing the posters produced by the students (see examples in Figures 3 and 4). Table 2 displays the results of that assessment in relation to the capacity of the model and corresponding proposals, to respond to sustainable urban planning challenges in general, and to green urban planning challenges in particular. In addition, Table 2 reveals the main merits and shortcomings of the model and shows how familiar different job sectors, professional fields and academic backgrounds are with the studied concepts, how much they use them, and their perception of the model and the students' works.

As is indicated in Table 2, 24 of the 75 contacted persons answered the questionnaire. By job sector, $62 \%$ of the respondents were employees of the cities where students applied the proposed model, $21 \%$ were teachers or researchers and $17 \%$ were practitioners. By academic background, $42 \%$ of the respondents were landscape architects, $17 \%$ were architects, $17 \%$ were environmental scientists, $8 \%$ were engineers, $8 \%$ were geographers and $8 \%$ were social scientists or licentiates in public administration. Regarding the professional field of practice, $25 \%$ of the respondents were working in environmental planning, $25 \%$ in city and urban planning, $21 \%$ in green area planning/landscape planning and $21 \%$ in landscape design, while the remaining $8 \%$ were involved in civil engineering or public administration.

Analysis of the results show that the most known urban nature concepts across all sectors, academic backgrounds and professional fields of practice are "ecosystem services", "sustainable storm water management" and "green infrastructure". The "nature-based solution" concept is less known except in the teachers/researchers (job sector), geographers (academic background) and green area planners (professional field) groups. The "urban metabolism" concept is only well known amongst academics (job sector) and architects and geographers (academic background). 
The level of use of the studied urban nature concepts is always lower than the level of familiarity amongst respondents. The most used concept is "ecosystem services", especially in the academic/research sector, amongst environmental scientists, geographers and social scientists (academic background) and in the professional field of Environmental Planning. The "green infrastructure" concept is also frequently used by city, green-area, landscape and environmental planners (professional field), by respondents with an academic background in environmental sciences, architecture, landscape architecture and geography, and by people working in the academic research sector or in local administration. The "nature-based solution" concept is not frequently used by the sampled academics/researchers but is used by city employees (sector) and by people with technical academic backgrounds, including engineers. Surprisingly, the "sustainable storm water management" concept loses relevance across the addressed job sectors, professional fields and academic backgrounds, and this situation becomes extreme in the case of the "urban metabolism" concept. Regarding the combination of the studied urban nature concepts, only teachers/researchers and environmental scientists confirmed to have and use an integrative or relational framework or model.

The proposed integrative or relational model for the studied urban nature concepts was perceived by all job sectors, academic backgrounds and professional disciplines as a promising model to support "green area planning", "sustainable city planning" "environmental urban sustainability", "sustainable storm water management" and for the "integration of the studied concepts". The potential of the model to increase "the role of urban nature in sustainable urban metabolisms" and to support "your professional or academic activity" generated very different opinions between the sampled groups and, in general, the model was perceived as less useful to support "social and economic urban sustainability". Regarding the responses of different groups, the proposed model was perceived as highly effective and useful by practitioners from the private sector and, to a lesser degree, by teachers and researchers. Regarding groups with different academic backgrounds, the model received a high score from architects, engineers and geographers, and an average score from landscape architects and environmental scientists, being the last group and the only one that had previously used a relational model for the studied concepts. Finally, amongst the studied professional fields, the respondents working in city and urban planning, landscape design and environmental planning rated the model positively, whereas professionals working in green area planning and landscape planning gave the model an average score, despite the high score that the same groups had given to the relational model to support green area planning and management.

Finally, evaluation of the students' works in the selected Baltic and Finnish cities was highly aligned with the assessment of the relational model explained above. Thus, the works produced by the students were perceived as particularly useful to support "sustainable green area planning and management", "environmental urban sustainability" and "sustainable storm water management" and, to a lesser degree, "sustainable city planning" and the "role of urban nature in sustainable urban metabolisms". Again, the works produced here were not particularly effective in dealing with "social and economic urban sustainability". Amongst the studied groups, practitioners from the private sector, architects and landscape designers assessed the produced works very positively whereas civil servants from the case study cities and respondents working in city and urban planning gave a positive assessment. Due to the small number of respondents in the social scientist, civil engineering and public administration groups, their positive assessment was not considered significant. 
Table 2. Assessment of the relational/integrative model for the use of urban nature concepts in sustainable urban planning by planners, academic experts and practitioners. Mean Likert scale values are presented.

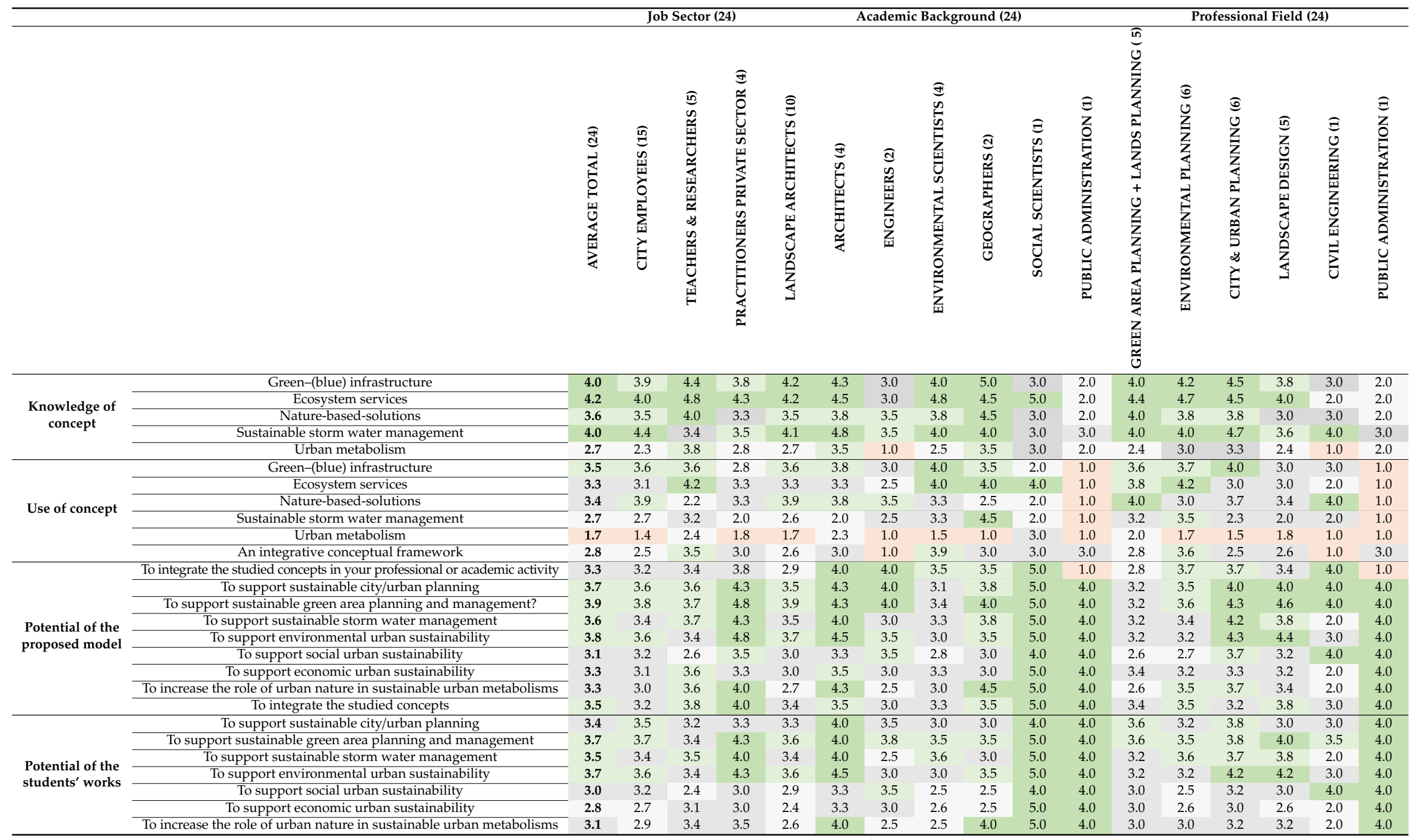




\section{Discussion}

This discussion is based on a critical reflection on the results produced in this research and how they can inform or support landscape planning education and urban planning practice in Finland. This critical reflection is connected with the overall potential of relational models to more effectively integrate different urban nature concepts into planning and, more specifically, with the process that led to the generation of the relational model proposed in this article and with the results of its use in higher education, as assessed by a wide range of external experts and potential users.

\subsection{About Relational Models for Urban Nature Concepts}

Concerning the general need for relational models connecting urban nature concepts, and as revealed by the results of the survey, few groups of users, regardless of their job sector, academic background or professional activity, have or use such types of models except for academics and environmental researchers.

Some of the studied urban nature concepts are quite well known amongst both academics and practitioners (e.g., GI, ESS, NBS and sustainable storm water management) but the level of knowledge decreases for other concepts such as urban metabolism. However, the level of use of these concepts is much lower than their level of familiarity amongst almost all types of users, suggesting that there is a gap between theory and practice.

In accordance with the results and with the selected literature advocating for the use of conceptual or relational models as a prerequisite to holistically analyse, plan and manage complex systems in general, and urban nature systems in particular [5], it would be advisable to promote their use in education in order to increase the capacity of future practitioners and decision makers to use or develop frameworks in which they can coherently integrate different concepts emerging from research.

\subsection{About the Relational Model as a Tool in (Landscape) Planning Education and Planning Practice}

Regarding the potential of the relational model to support landscape and urban planning education, teachers and researchers found it to be a promising tool, both in general and in their specific academic fields. This opinion was confirmed by the positive assessment that the same group of people, together with private practitioners and city employees, gave to the works of the students using the model. Likewise, both city employees and private practitioners found the relational model adequate to integrate the concepts, especially in sustainable city/urban planning, green area planning, storm water management and environmental planning in Finnish cities.

The suggested relational model combines various urban nature and sustainable-planning concepts (e.g., GI, ESS, NBS, natural capital, socio-ecological systems, etc.) and offers a conceptual framework for more performative natures in more sustainable cities. Additionally, through the external assessment, these results suggest potential ways to improve the model, its use in higher education and directions for future research.

In contrast to other conceptual models that focus on one particular urban nature concept and its relationship with other related concepts, or to studies focused on comparative terminological investigations, this model aims to offer an operational framework strictly focused on the relationship between urban nature concepts and their integrated use in urban sustainability and planning. Because of this focus, some specific aspects or meanings of the concepts might have been partially overlooked and some particular details of their methodological use might not have been presented. However, they would be perfectly compatible with the proposed model, such as the green infrastructures planning principles proposed by Hansen and Pauleit (2014), the practical and governance implications of using ESS in urban landscapes as defined by Haase et al. (2014) [6,9] or a more consistent integration of the biodiversity concept, either as an ecosystem service or as an overarching goal per se $[43,44]$. Somehow, this was an assumed and logical consequence of focusing on integration and in the definition of a more 
consistent and operational syntax between existing and emerging urban nature concepts, rather than in independent concepts.

From a content and typological point of view and compared to other models, the proposed relational model aims to include a much wider number of concepts and to further elaborate their complementarities and connections (Figure 2). The result is a model that formally and conceptually combines a layered approach to urban nature and an embedded approach to the concepts framing and directing its planning and management. Therefore, as a result of this approach, urban sustainability and resilience, together with human well-being and biodiversity, are perceived as overarching goals, and the urban socio-ecological system as the system were urban nature is inserted and as the all-encompassing thinking and epistemological paradigm.

Moreover, the formulation in the model of urban nature as a layered combination of a spatial network and their associated cascade of processes, functions services and benefits [11], has clear connections with landscape ecology theory and the proposed interdependence of structure, function and change or pattern and process [61,62]. These analogies can be extended to the perception of sustainability as a paradigm driving the evolution of socio-ecological systems.

The methodology followed for the development of the relational model was effective and rigorous, but as revealed during the semantic review (Table 1), some additional concepts might have been included in the initial search in order to integrate them more clearly in the model (e.g., quality of life, human well-being or biodiversity).

The parameters defined by Maes and Poels (2007) offer a solid framework for the analysis of the quality of a conceptual or relational model [32]. Thus, in terms of semantic quality, the proposed model starts with a semantic alignment of concepts in order to avoid duplication and misunderstanding. However, this semantic work could have been evaluated and endorsed by different types of users after checking if the proposed definitions conform to their own principles, experiences and expectations. Secondly, in terms of systemic quality (ease of understanding) and of usefulness, the model was found highly useful for integrating the concepts. This positive feedback was provided by all the types of users who responded to the survey, regardless of their job sector, academic background or professional field. Finally, regarding the user satisfaction factor, the students who used the model to develop their proposals found the model extremely useful for combining different concepts in a coordinated and complementary manner. Nevertheless, despite the overall positive assessment of the model, this research is perceived as an initial step towards a more consistent definition and validation of relational models serving the needs of both research and practice.

\subsection{About the Academic Results Produced with the Proposed Relational Model}

From an educational point of view, the work produced by students on the basis of the relational model shows a high level of integration of the considered urban nature concepts as confirmed through the external and quantitative evaluation of the deliverables produced in the green area planning course.

From a cognitive perspective, the model was aimed at promoting systems of thinking and relational skills in an increasingly complex world, in which one of the main challenges for both students and practitioners is to develop their capacity to integrate existing and emerging concepts in a coherent and operational framework. Thus, complex systems theory is gaining relevance in a wide range of professions, where there is a real need to "understand the relationship of general complex systems principles to domain-specific features of such systems" [63] (p. 23). This challenge and goal have also been recognized in the landscape architecture field [64].

Following these pedagogical findings, it can be concluded that the elaboration of relational models is a key exercise in itself to promote systems and relational thinking. Consequently, in the 2020 version of the green area planning course, the presented model was just used as an activator for the generation of relational models by the students themselves. The outcomes from this course showed an even deeper level of understanding of the addressed concepts and of their potential in urban and landscape planning and management. 
As displayed in Table 2, the scores obtained by the students' works were slightly lower that of those obtained by the relational model itself. This can be explained by the limited amount of time, resources and expertise of the students, and suggests the need of deepening the connections between conceptual integrative models, education and practice in order to fulfil the full potential of the models. Moreover, the decision of applying and testing the model in a studio course of a master programme instead of in a professional practice or in a city office provided a particularly flexible and speculative framework and, in addition, was also perceived as a way to generate new and innovative modes of practice and educate future gamechangers. Nevertheless, the close collaboration with the cities where the proposals were developed ensured a smooth flow of information between cities and students during the whole process.

\subsection{About the External Assessment or Validation of the Model and the Produced Outcomes by Different Types of Stakeholders in the Landscape and Urban Planning Process}

The external assessment of both the relational model and the results produced by the students was accomplished through a survey providing quantitative feedback about the utility of the model and its capacity to respond to different urban and landscape planning challenges. This approach is aligned with other initiatives aimed at validating conceptual models in a more consistent and objective way $[43,44]$. The inclusion of different types of respondents, organized according to job sectors, academic background and professional field of practice, gave the survey an additional value by revealing how familiar different types of users are with some urban nature concepts, and how much they could benefit from the development of more clearly articulated connections between them.

Due to the limited size of the surveyed sample, results of this work mainly have a qualitative value. However, they disclose patterns and potential links that deserve further and more comprehensive investigation. Despite these limitations, the results suggest new lines of action to improve the relational model in order to address social and economic urban sustainability more clearly and to facilitate the integrated and articulated use of urban nature concepts in education, research and practice. Moreover, the results can also activate a critical and constructive diagnosis of the current usage of urban nature concepts and integrative models in different academic disciplines, job sectors and professional fields, challenging existing boundaries and promoting systemic and interdisciplinary thinking.

\section{Conclusions}

Overall, this research shows the benefits of defining relational models to work in research, education and practice, with different and interconnected concepts operating in complex systems. The methodology to define this kind of model emerged in this case from a specific theme: urban nature in sustainable urban planning, but it has the potential to be applied in other fields or topics. Additionally, the definition and use of these kind of models in education can open new possibilities to increase the needed linkage between research and education whereas the assessment by external evaluators of the model itself and the subsequent academic results might define a potential and promising path to reinforce dialogue between academia and practice.

In a more specific sense, the conducted research reveals that the level of transfer from theory to practice for the studied concepts is still in an early stage and that emphasis has been placed on the generation of concepts rather than in their articulation and their connection to integrative landscape and urban planning. Moreover, the presented results show the potential of the proposed relational model to support landscape and urban planning education by promoting an integrative and coordinated use of novel urban nature concepts emerging from research and feeding professional practice.

In a broader sense, and as unveiled by the critical assessment of the students' works, the development and application of this kind of models promote conceptual, relational, critical and systemic thinking, which are considered essential cognitive skills to work in complex socio-ecological systems. From the perspective of sustainable landscape and urban planning, the proposed model and the subsequent students' proposals were found highly relevant and useful for different types of 
users, hinting at the need to make more available, clear syntaxes between urban nature concepts and suggesting the potential of the proposed relational model to be disseminated, used in practice and perfected on the basis of the detected weaknesses and strengths.

Funding: This research received no external funding.

Acknowledgments: To the students of the Green Area Planning course for their full commitment and engagement.

Conflicts of Interest: The author declares no conflict of interest.

\section{References}

1. Angelstam, P.; Andersson, K.; Annerstedt, M.; Axelsson, R.; Elbakidze, M.; Garrido, P.; Grahn, P.; Jönsson, K.I.; Pedersen, S.; Schlyter, P.; et al. Solving Problems in Social-Ecological Systems: Definition, Practice and Barriers of Transdisciplinary Research. AMBIOS 2013, 4, 254-265. [CrossRef] [PubMed]

2. Davies, C.; Hansen, R.; Rall, E.; Pauleit, S.; Lafortezza, R.; De Bellis, Y.; Santos, A.; Tosics, I. The Status of European Green Space Planning and Implementation Based on an Analysis of Selected European City-Regions; EU FP7 project GREEN SURGE, Deliverable D5.1; University of Copenhagen: Copenhagen, Denmark, 2015.

3. Pauleit, S.; Zölch, T.; Hansen, R.; Randrup, T.B.; Konijnendijk van den Bosch, C. Nature-Based Solutions and Climate Change-Four Shades of Green. In Nature-Based Solutions to Climate Change Adaptation in Urban Areas. Theory and Practice of Urban Sustainability Transitions; Kabisch, N., Korn, H., Stadler, J., Bonn, A., Eds.; Springer: Berlin/Heidelberg, Germany, 2017; pp. 29-49.

4. Nesshöver, C.; Assmuth, T.; Irvine, K.; Rusch, G.; Waylen, K.; Delbaere, B.; Haase, D.; Jones-Walters, L.; Hansm, K.; Esztern, K.; et al. The Science, Policy and Practice of Nature-Based Solutions: An Interdisciplinary Perspective. Sci. Total Environ. 2017, 79, 1215-1227. [CrossRef] [PubMed]

5. Van Kamp, I.; Leidelmeijera, K.; Marsmana, G.; Hollander, A. Urban environmental quality and human well-being Towards a conceptual framework and demarcation of concepts; a literature study. Landsc. Urban Plan. 2003, 65, 5-18. [CrossRef]

6. Hansen, R.; Pauleit, S. From Multifunctionality to Multiple Ecosystem Services? A Conceptual Framework for Multifunctionality in Green Infrastructure Planning for Urban Areas. AMBIO 2014, 43, 516-529. [CrossRef]

7. Lennon, M.; Scott, M.; Collier, M.; Foley, K. Developing green infrastructure 'thinking': Devising and applying an interactive group-based methodology for practitioners. J. Environ. Plan. Manag. 2015, 59, 843-865. [CrossRef]

8. Lähde, E.; Di Marino, M. Multidisciplinary collaboration and understanding of green infrastructure Results from the cities of Tampere, Vantaa and Jyväskyla. Urban For. Urban Green. 2019, 40, 63-72. [CrossRef]

9. Haase, D.; Frantzeskaki, N.; Elmqvist, T. Ecosystem Services in Urban Landscapes: Practical Applications and Governance Implications. AMBIO 2014, 43, 407-412. [CrossRef]

10. Lafortezza, R.; Davies, C.; Sanesi, G.; Konijnendijk, C.C. Green Infrastructure as a tool to support spatial planning in European urban regions. iForest 2013, 6, 102-108. [CrossRef]

11. Haines-Young, R.; Potschin, M. The links between biodiversity, ecosystem services and human well-being. In Ecosystem Ecology: A New Synthesis; Frid, C., Raffaelli, D.G., Eds.; Cambridge University Press: Cambridge, UK, 2010; pp. 110-139.

12. Tzoulas, K.; Korpela, K.; Venn, S.; Yli-Pelkonen, V.; Kazmierczak, A.; Niemela, J.; James, P. Promoting ecosystem and human health in urban areas using Green Infrastructure: A literature review. Landsc. Urban Plan. 2007, 81, 167-178. [CrossRef]

13. Tidball, K.G.; Krasny, M.E. Urban Environmental Education From a Social-Ecological Perspective: Conceptual Framework for Civic Ecology Education, Cities and the Environment. Cities Environ. (CATE) 2011, 3. Available online: https://digitalcommons.lmu.edu/cgi/viewcontent.cgi?referer=https:/www.google.com.hk/ \&httpsredir $=1 \&$ article $=1057 \&$ context $=$ cate \&sei-redir $=1$ (accessed on 10 January 2020).

14. Muhar, A.; Raymond, C.R.; van den Born, R.J.G.; Bauer, N.; Böck, K.; Braito, M.; Buijs, A.; Flint, C.; de Groot, W.T.; Ives, C.D.; et al. A model integrating social-cultural concepts of nature into frameworks of interaction between social and natural systems. J. Environ. Plan. Manag. 2018, 61, 756-777. [CrossRef]

15. Galan, J.; Perrotti, D. Incorporating Metabolic Thinking into Regional Planning: The Case of the Sierra Calderona Strategic Plan. Urban Plan. 2019, 4, 152-171. [CrossRef] 
16. Kambites, C.; Owen, S. Renewed prospects for green infrastructure planning in the UK. Plan. Pract. Res. 2007, 21, 483-496. [CrossRef]

17. Mell, I.C. Green Infrastructure: Concepts, Perceptions and its Use in Spatial Planning. Ph.D. Thesis, Newcastle University, Newcastle, UK, 2010.

18. Armstrong, H. Design studios research: An emerging paradigm for landscape architecture. Landsc. Rev. 1999, 5, 5-25.

19. Yin, R.K. Applications of Case Study Research; Sage: Thousand Oaks, CA, USA, 1993.

20. Baum, H. Teaching practice. J. Plan. Educ. Res. 1997, 17, 21-29. [CrossRef]

21. Shepherd, A.; Cosgriff, B. Problem based learning: A bridge between planning education and planning practice. J. Plan. Educ. Res. 1998, 17, 348-357. [CrossRef]

22. Kumar, M.; Kogut, G. Students' perceptions of problem based learning. Teach. Dev. 2006, 10, 105-116. [CrossRef]

23. Higgins, M.; Aitken-Rose, E.; Dixon, J. The Pedagogy of the Planning Studio: A View from Down Under. J. Educ. Built Environ. 2009, 4, 8-30. [CrossRef]

24. Galan, J. Pedagogical and Academic Reflections from the iWater Summer Schools: Storm Water Management in Urban and Landscape Planning. In Landscapes of Conflict, Proceedings of the ECLAS-2018 conference, Ghent, Belgium, 9-12 September 2018; Delarue, S., Dufour, R., Eds.; University of Ghent: Ghent, Belgium, 2018; pp. 560-568.

25. Frank, A. Three decades of thought on planning education. J. Plan. Lit. 2006, 21, 15-67. [CrossRef]

26. Higgins, M.; Simpson, F. Work-Based Learning Within Planning Education: A Good Practice Guide; University of Westminster Press for the Discipline Network in Town Planning: London, UK, 1997.

27. Patton, M. Qualitative Evaluation and Research Methods, 2nd ed.; SAGE Publications, Inc.: California, UK, 1990.

28. Richardson, L. Writing: A Method of Inquiry. In Handbook of Qualitative Research; SAGE: Thousand Oaks, CA, USA, 1994; pp. 516-529.

29. Margoluis, R.; Stem, C.; Salafsky, N.; Brown, M. Using conceptual models as a planning and evaluation tool in conservation. Eval. Program Plan. 2009, 32, 138-147. [CrossRef]

30. Oliver-Hoyo, M.; Allen, D.D. The Use of Triangulation Methods in Qualitative Educational Research. J. Coll. Sci. Teach. 2006, 35, 42-47.

31. Mehmood, K.; Cherfi, S.S.S. Evaluating the Functionality of Conceptual Models. In Advances in Conceptual Modeling-Challenging Perspectives. ER 2009. Lecture Notes in Computer Science; Heuser, C.A., Pernul, G., Eds.; Springer: Berlin/Heidelberg, Germany, 2009; Volume 5833.

32. Maes, A.; Poels, G. Evaluating quality of conceptual modelling scripts based on user perceptions. Data Knowl. Eng. 2007, 63, 701-724. [CrossRef]

33. Ahern, J. Spatial Concepts, Planning-Strategies, and Future Scenarios: A Framework Method for Integrating Landscape Ecology and Landscape Planning. In Landscape Ecological Analysis; Springer: New York, NY, USA, 1999; pp. 176-201.

34. Forman, R.T.T. Urban Ecology: Science for Cities; Cambridge University Press: Cambridge, UK, 2014.

35. Waldheim, C. Landscape as Urbanism; Princeton University Press: Princeton, NJ, USA, 2016.

36. Mostafavi, M. Why Ecological Urbanism? Why Now. In Ecological Urbanism; Mostafavi, M., Doherty, G., Eds.; Lars Mûller Publishers: Zurich, Switzerland, 2016.

37. Galan, J. New paradigms and concepts for urban nature: An integrative model practical application in landscape planning education at Aalto university. In Lessons from the Past, Visions for the Future: Celebrating One Hundred Years of Landscape Architecture Education in Europe, Proceedings of the ECLAS-2019 conference, Ås, Norway, 16 September 2019; Egoz, S., Gao, L., Eds.; European Council of Landscape Architecture Schools (ECLAS): Ås, Norway, 2019; pp. 215-219.

38. Lima, M. Visual Complexity: Mapping Patterns of Information; Princeton University Press: Princeton, NJ, USA, 2011.

39. Deming, M.E.; Swaffield, S. Landscape Architectural Research: Inquiry, Strategy, Design; John Wiley \& Sons: Hoboken, NJ, USA, 2011.

40. Van den Brink, A.; Bruns, D.; Tobi, H.; Bell, S. (Eds.) Research in Landscape Architecture: Methods and Methodology; Routledge: London, UK, 2017.

41. Antrop, M.; Van Eetvelde, V. Landscape Perspectives: The Holistic Nature of Landscape; Springer: Berlin/Heidelberg, Germany, 2017. 
42. Naveh, Z. What is holistic landscape ecology? A conceptual introduction. Landsc. Urban Plan. 2000, 50, 7-26. [CrossRef]

43. De Groot, R.; Jax, K.; Harrisson, P. Links between Biodiversity and Ecosystem Services. In OpenNESS Ecosystem Services Reference Book; EC FP7 Grant Agreement no. 308428; Potschin, M., Jax, K., Eds.; ECNC-European Centre for Nature Conservation: Tilburg, Netherlands, 2016.

44. Mace, G.M.; Norris, K.; Fitter, A.H. Biodiversity and ecosystem services: A multi-layered relationship. Trends Ecol. Evol. 2012, 27, 19-26. [CrossRef]

45. Niesenbaum, R.A. The Integration of Conservation, Biodiversity, and Sustainability. Sustainability 2019, 11, 4676. [CrossRef]

46. About the Sustainable Development Goals-United Nations Sustainable Development. Available online: https://www.un.org/sustainabledevelopment/sustainable-development-goals/ (accessed on 10 January 2020).

47. European Commission. The Forms and Functions of Green Infrastructure; European Commission: Brussels, Belgium, 2016.

48. Millennium Ecosystems Assessment. Ecosystems and Human Well-Being: Ecosystems and Their Services; Millennium Ecosystems Assessment: Washington, DC, USA, 2005.

49. Daily, G.C.; Kareiva, P.; Polasky, S.; Ricketts, T.H.; Tallis, H. Mainstreaming natural capital into decisions. In Natural Capital. Theory E Practice of Mapping Ecosystem Services; Kareiva, P., Tallis, H., Ricketts, T.H., Daily, G.C., Polasky, S., Eds.; Oxford University Press: Oxford, UK, 2011; pp. 3-14.

50. European Commission. Towards an EU Research and Innovation Policy Agenda for Nature-Based Solutions $\mathcal{E}$ Re-Naturing Cities; European Commission: Brussels, Belgium, 2015.

51. Maes, J.; Jacobs, S. Nature-Based Solutions for Europe's Sustainable Development. Conserv. Lett. 2017, 10, 121-124. [CrossRef]

52. Haase, D. Reflections on urban landscapes, ecosystems services and nature-based solutions in cities. Plan. Theory Pract. 2016, 17, 276-280.

53. SUSDRAIN. Sustainable Drainage; CIRIA: London, UK, 2019.

54. Glaser, M.; Krause, G.; Ratter, B.; Welp, M. Human-Nature-Interaction in the Anthropocene. In Potential of Social-Ecological Systems Analysis; Routledge: London, UK, 2008.

55. Baccini, P. A city's metabolism: Towards the sustainable development of urban systems. J. Urban Technol. 2007, 4, 27-39. [CrossRef]

56. Kennedy, C.; Cuddihy, J.; Engel-Yan, J. The changing metabolism of cities. J. Ind. Ecol. 2007, 11, 43-59. [CrossRef]

57. Wackernagel, M.; Rees, W.E. Perceptual and structural barriers to investing in natural capital: Economics from an ecological footprint perspective. Ecol. Econ. 1997, 20, 3-24. [CrossRef]

58. Costanza, R.; D'Arge, R.; De Groot, R.; Farber, S.; Grasso, M.; Hannon, B. The value of ecosystem services: Putting the issues in perspective. Ecol. Econ. 1998, 25, 67-72. [CrossRef]

59. Berkes, F.; Folke, C.A. systems perspective on the interrelations between natural, human-made and cultural capital. Ecol. Econ. 1992, 5, 1-8. [CrossRef]

60. Tillie, N. Rotterdam People make the Inner City: Densification + Greenification = Sustainable City; Rotterdam Mediacenter, NL: Rottherdam, The Netherlands, 2012.

61. Forman, R.T.T.; Godron, M. Landscape Ecology; John Wiley \& Sons: Hoboken, NJ, USA, 1986.

62. Forman, R.T.T. Land Mosaics: The Ecology of Landscapes and Regions; Cambridge University Press: Cambridge, UK, 1995.

63. Jacobson, M.J.; Wilensky, U. Complex Systems in Education: Scientific and Educational Importance and Implications for the Learning Sciences. J. Learn. Sci. 2006, 15, 11-34. [CrossRef]

64. Murphy, M.D.; Hedfors, P. Systems theory in landscape architecture. In Conference: Urban Nature: Council of Educators in Landscape Architecture (CELA), Los Angeles, USA, April, 2011; Council of Educators in Landscape Architecture CELA: Raleigh, NC, USA, 2011; pp. 1-13.

(C) 2020 by the author. Licensee MDPI, Basel, Switzerland. This article is an open access article distributed under the terms and conditions of the Creative Commons Attribution (CC BY) license (http://creativecommons.org/licenses/by/4.0/). 